\title{
Evaluation of the Adsorption Capacity of the Coconut Shell and Palm-Kernel Shell Adsorbents Powder for the Sorption of Cadmium (11) Ions from Aqueous Solution
}

\author{
${ }^{*}$ Eruola A.O and *Ogunyemi I.O \\ *Chemical Science Department Yaba College of Technology, Yaba Lagos
}

\begin{abstract}
Environmental contamination of toxic metals accumulation in food chain is of global concern. Biosorption type of adsorption process is an economical tool in waste water treatment which is an alternative metal adsorption compares to high cost conventional methods like precipitation and reverse osmosis. The study examined adsorption capacities of two palm shell powder absorbents in the removal of Cd (11) ions from synthetic waste water. Coconut (Cocos nucifera) and palm-kernel (Elaeis guineensis) shell powder adsorbent used for $\mathrm{Cd}$ (11) ion sorption were developed from agricultural bye products. The procedure involved comparison of the performance of these adsorbents with each other by metal binding capacities, initial metal ion concentrations, ionic strengths and contact time. The adsorption capacities per unit gram of each of the adsorbents at equilibrium time, optimum $\mathrm{pH}, 200 \mathrm{r} \mathrm{p} \mathrm{m} \mathrm{speed,} 25^{\circ} \mathrm{C}$ temperature under 10 to $50 \mathrm{mg} \mathrm{kg}^{-1}$ initial metal concentration was determined. The binding capacities for Cd (11) ion are 5.34 to $37.42 \mathrm{mg} \mathrm{kg}^{-1}$ for coconut shell relative to 0.32 to 4.75 for palm-kernel shell adsorbent at optimum contact time of 5 hrs. The long contact time for the sorbent metal adsorption indicated that the predominant mechanism was physisorptions. The optimum $\mathrm{pH}$ value for, Cd (II) ion removals on coconut and palm kernel shells powder are 5.0 and 6.0, respectively. Adsorption kinetics was verified by pseudo-first order (Lagergren) rate and pseudo-second order (Ho-model) rate models. The kinetic of the sorption mechanism indicate that pseudo-first order model provides a more appropriate description of the Cd (11) ion sorption on the adsorbents. Adsorption isotherms patterns of both adsorbents were modeled using Langmuir and Freundlich isotherms. Based on correlation coefficient $\left(R^{2}\right)$ values, equilibrium data found fitted well to the Freundlich isotherm. It is concluded that the two palm- shells can be use as an effective adsorbents for removal of toxic Cd (11) ion but coconut shell has the greater potential over palm-kernel shell.
\end{abstract}

Keywords: Adsorption isotherm; Cd(II); kinetics; coconut shell; palm kernel shell.

\section{Introduction}

The presence of heavy metals in the environment has become a major threat to plant, animals and human life due to their bioaccumulations tendency and toxicity and therefore must be removed from municipal and industrial effluents before discharge. In recent years much public interest focused on the subject of environmental contamination with toxic elements such as lead, copper, zinc, cadmium, nickel, chromium, mercury and manganese which are most harmful for public health. A major pathway of these toxic metals release into the environments is through the anthropogenic activities like mining, industrial effluents, agricultural mismanagements, sewage disposal and burning of fossil fuel.

Cadmium is a toxic heavy metal that is omnipresent in its distribution around the ecosystem. There has been an increasing use of cadmium for electroplating, batteries, alloys, pigments, stabilizers for catalysts and in semiconductors and TV tube phosphors (Horsfall et al,.2004).

Adsorption process is highly efficient, useful, simple and insensitive to toxic substances, effective, less environmentally degrading and economical tool ( Loubna et al,.2007). The major advantages of adsorption technologies are its effectiveness in reducing the concentration of heavy metal ions to very low levels and the use of inexpensive adsorbent materials. However, most conventional waste water treatment techniques for removal of metals such as filtration, activated charcoal, reverse osmosis, chemical precipitation, solvent extraction, ion exchange and membrane separation. These are not economically viable for small scale industries due to huge capital investment. It is therefore necessary to search for low-cost techniques that may be effective, less environmentally degrading and economical for industrial usage. Adsorption has been shown to be an economically feasible alternative method for removing heavy metals from waste water and water supplies (Horsfall and Spiff,. 2004)). In the purification process, low cost adsorbent are preferred.

The use of agricultural by- products for the sorption of valuable metals from waste water has continued to attract considerable attention because they are cheap source of biosorbents, sludge free and involve small initial cost and land investment.( Horsfall et al,. 2004).These includes the use of numbers of agricultural materials such as sugar cane cabon (Krishnan,et al,.2003), spent grain (Low,. et al 2000.) rice husk (Naiya, et 
al., 2009). Cassava waste (Horsfall, et al 2004.).Groundnut (Okieiman et al,.1991) wild cocoyam biomass ( Horsfall and Spiff,. 2004) wheat bran(Loubna et al,.2007), The aim of this study suggest the possibility of developing good adsorbents from agricultural waste and to and asses the adsorption potential of coconut and palm-kernel shell to adsorb $\mathrm{Cd}$ (11) ions from aqueous solutions.

\section{Sources of materials}

The agricultural waste materials (coconut and palm-kernel shell) were collected from the Federal University of Agriculture Abeokuta. All the reagents used were of analytical grade.

\section{Preparation of adsorbent materials}

The coconut and palm-kernel shell were thoroughly washed in water to remove mud dusts and other kinds of dirt's. They were then sun- dried before being finally oven- dried at $100-105^{\circ} \mathrm{c}$ for eight hours. The cleaned, dried materials were pulverized to $0.85 \mathrm{~mm}$ mesh size with the aid of a grinder. Each adsorbent powder so prepared was packed in separated polythene bag and labeled accordingly.

\section{Methodology}

Sorption studies were carried out at desired $\mathrm{pH}$ value, contact time and ionic strength. Different initial concentration of Cd (II) ion solutions were prepared by proper dilution from stock $1000 \mathrm{mg} / \mathrm{l} \mathrm{metal}$ ion standard solutions. Standard metal ion solutions was prepared from $\mathrm{Cd}(\mathrm{NO} 3)_{2}$. $\mathrm{pH}$ of the test solution was monitored by adding $0.1 \mathrm{M} \mathrm{HCl}$ and $0.1 \mathrm{M} \mathrm{NaOH}$ solution as required (Horsfall and Spiff,. 2004). The amount of each of the biosorbent was then added to the $\mathrm{Cd}$ (II) ion solution in the conical flask and stirred for the desired contact time using a mechanical shaker at $200 \mathrm{r} \mathrm{p} \mathrm{m}$ speed. The time required for reaching equilibrium condition estimated by drawing samples at regular interval of time till the equilibrium was reached. The content of the Cd (II) ion in the test flask was separated from each of the biosorbent by filtration through a filter paper and was analyzed by Flame Atomic Emission Spectrometer. The samples were analyzed three times and the mean values each were computed. The amount of $\mathrm{Cd}$ (II) ion adsorbed per unit mass of each of the biosorbent was evaluated by using following equations:

$\mathrm{Qe}=(\mathrm{Co}-\mathrm{Ce}) \mathrm{V} / \mathrm{m}$.

Co is the initial Cd (11) concentrations ( $\mathrm{mg} / \mathrm{l})$;

$\mathrm{Ce}$ is the $\mathrm{Cd}^{2+}$ concentration at equilibrium $(\mathrm{mg} / \mathrm{l})$,

$\mathrm{m}$ is the adsorbent mass $(\mathrm{m})$,

$\mathrm{V}$ is the solution volume (1).

Calculations were made by using these data and adsorption curves were obtained.

\section{Effect of initial metal ion concentration}

\section{Results and discussion}

The time taken to attain equilibrium for $\mathrm{Cd}(11)$ ion at neutral $\mathrm{pH}$, temperature of $25^{\circ} \mathrm{C}$, initial rate concentrations of 5,10, 15 and $20 \mathrm{mg} \mathrm{kg}^{-1}$ and centrifugation speed of $200 \mathrm{r} \mathrm{p} \mathrm{m}$ using $1 \mathrm{~g}$ each of the adsorbents (coconut and palm kernel shell powder) were shown in Fig 1 and 2.

It was observed that the amount of $\mathrm{Cd}$ (11) ion adsorbed per unit mass of each of the adsorbent increased significantly with increase initial rate concentrations of the metal ion and later reached a plateu where the adsorption capacities became independent of initial metal concentrations for the series. The metal uptake mechanism is particularly dependent on the initial cadmium metal concentration at low concentrations because metal ions are absorbed by specific active sites

( Horsfall, and Spiff,. 2005). That is the fast initial adsorption is due to larger surface area of the adsorbents at the beginning of adsorption reaction, while with increasing metal concentrations the binding sites become more quickly saturated as the amount of biomass concentration remained constant . The amount of the metal ion each in their different series shows the same magnitude in their removal but varies in the adsorption capacity. The structural aspects of the polymeric backbone are also important factors affecting $\mathrm{Cd}(11)$ ions sorption. The presence of hydroxyl functional group on the surface of cellulose component of coconut and palm kernel shell powder interacts with $\mathrm{Cd}$ (11) atom which significantly improved the binding capacity of the sorbents and the process proceeded rapidly. 


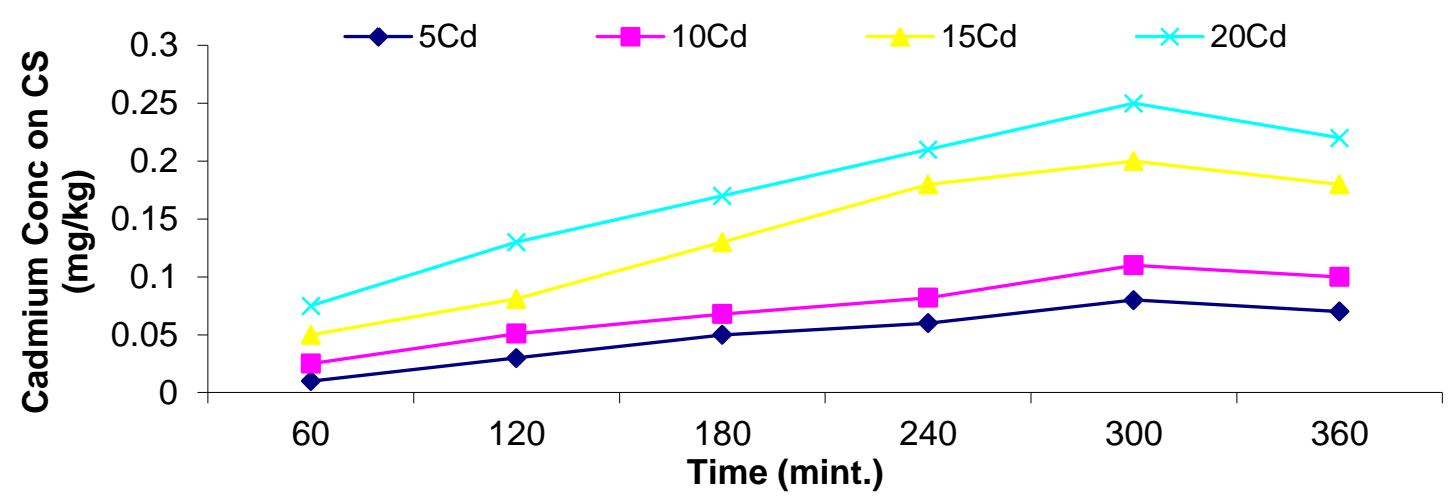

Fig 1: Effect of initial metal ion concentration on $\mathrm{Cd}(11)$ ion removal at neutral $\mathrm{pH}$, temperature of $25^{\circ} \mathrm{c}$ and agitation speed of $200 \mathrm{rpm}$ for Coconut shell powder adsorbent.

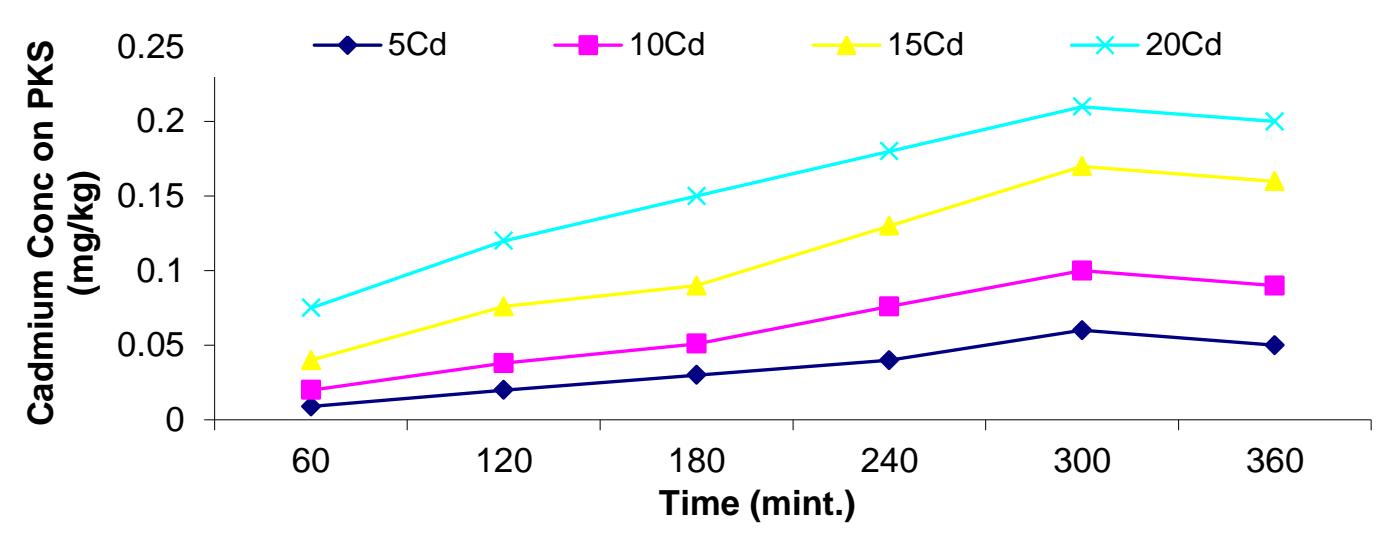

Fig 2: Effect of initial metal ion concentration on $\mathrm{Cd}(11)$ ion removal at neutral $\mathrm{pH}$, temperature of $25^{\circ} \mathrm{c}$ and agitation speed of $200 \mathrm{rpm}$ for palm kernel shell powder adsorbent.

\section{Effect of contact time}

The effect of contact time on the rate of $\mathrm{Cd}$ (11) ion uptake onto coconut and palm kernel adsorbents is shown in Fig 3. At the beginning of Cd (11) removal capacities increased quickly and then after 240 min, the rate decreased sharply and eventually reached a constant peak after at 300 minutes of the adsorption irrespective of concentrations $\left(5,10,15\right.$ and $\left.20 \mathrm{mg} \mathrm{kg}^{-1}\right)$. After about 300 minutes, the adsorbed quantity of the Cd (11) ion remains constant on the two adsorbents. The two stages of sorption mechanism with the first rapid and quantitatively predominant and the second slower and quantitatively insignificant, has been extensively reported in literature (Saeed, et al,.2005), ( Runping, et al. 2008) using another adsorbent. This behavior gives away a slow approach to equilibrium. The nature of adsorbent and its available sorption sites affected the time needed to reach the equilibrium. The metal ions removal capacity increased with an increasing contact time before equilibrium is reached. It is observed that $\mathrm{Cd}(11)$ ion optimum removal capacity of coconut shell and palmkernel shell sorbent are $0.26 \mathrm{mg} \mathrm{kg}^{-1}$ and $0.22 \mathrm{mg} \mathrm{kg}^{-1}$ respectively at optimum contact time of $5 \mathrm{hrs}$. The long contact time of 5 hours observed to reach equilibrium for all the metal ions indicated that the predominant mechanism was physisorptions (Saeed, et al,.2005).This encourage easy removal of the adsorbed heavy metals or regeneration of the spent adsorbent. 


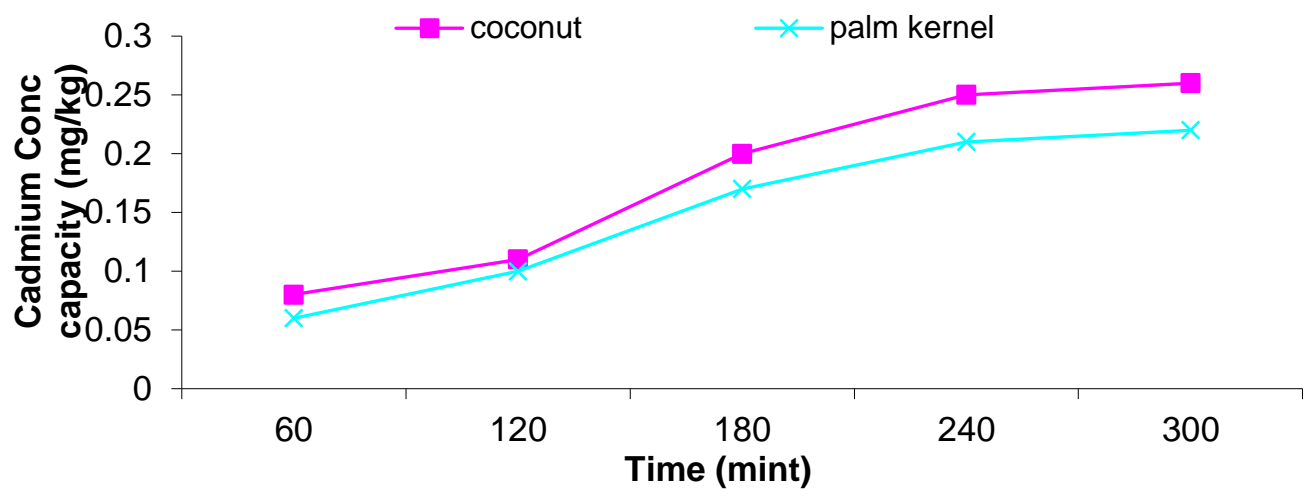

Figure 3: Effect of contact time on Cd (11) ion removal at neutral $\mathrm{pH}$ temperature of $25^{\circ} \mathrm{c}$ and agitation speed of $200 \mathrm{rpm}$ for coconut and palm kernel shell powder adsorbents.

\section{Kinetic treatment of experimental data}

The mechanism of adsorption for the heavy metals was subjected to both pseudo-first order Lagergren, (1898) and pseudo second order Ho and Mckay (1999) equations at the initial metal concentrations of $5 \mathrm{mg} \mathrm{kg}^{-1}$

\section{Pseudo first order or Lagergren equation}

Log $[\mathrm{Qe}-\mathrm{Q}]=\log \mathrm{Qe}-\mathrm{k}_{1} / 2.303 \mathrm{t}$

A linear plot of $\log [\mathrm{Qe}-\mathrm{Q}]$ against ${ }^{\mathrm{t}} \mathrm{t}$ ' indicates the conformity with the model

$\mathrm{Qe}=$ mass of metal adsorbed at equilibrium $\left(\mathrm{mg} \mathrm{kg}^{-1}\right)$

$\mathrm{Q}=$ mass of metal adsorbed at time " $\mathrm{t}$ " $\left(\mathrm{mg} \mathrm{kg}^{-1}\right)$

" $\mathrm{t} "=$ time for adsorption $(\mathrm{hrs})$

$\mathrm{k}_{1}=$ equilibrium rate constants for $1^{\text {st }}$ order

Pseudo second order or Ho (2004) equation

$\mathrm{t} / \mathrm{Qe}=1 / \mathrm{k}_{2} \mathrm{Qe}^{2}+\mathrm{t} / \mathrm{Qe}$

A linear plot of $t / Q e$ against' $t$ ' indicates conformity with the model

$\mathrm{Qe}=$ mass of metal adsorbed at equilibrium $\left(\mathrm{mg} \mathrm{kg}^{-1}\right)$

" $\mathrm{t}$ "= time for adsorption (hrs)

$\mathrm{k}_{2}=$ equilibrium rate constants for $2^{\text {nd }}$ order.

The rate of $\mathrm{Cd}$ (11) ion adsorption conformed with pseudo- first order (Lagergren) as shown in the Fig 4 and 5 for the sorbents.

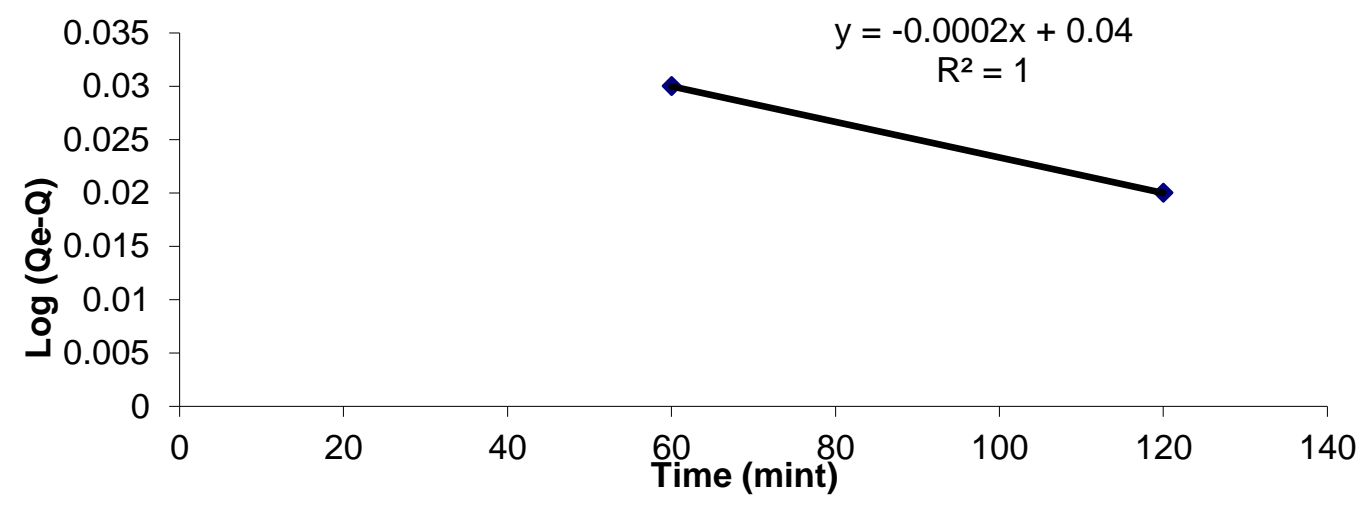

Fig 4: Pseudo first order plot for $\mathrm{Cd}$ (11) ion removal using coconut shell at neutral pH. 


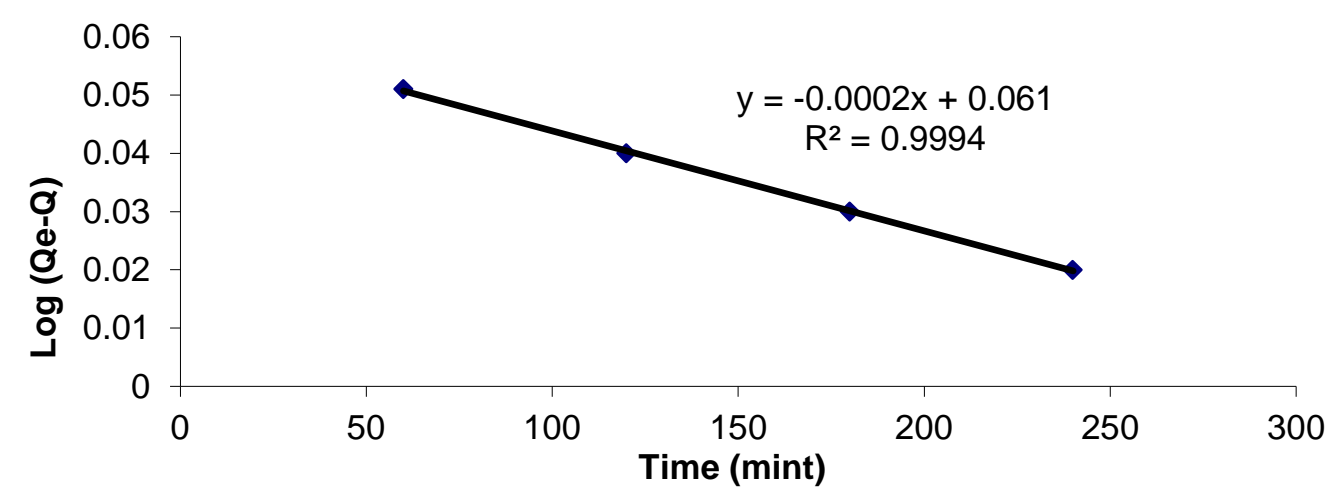

Fig 5: Pseudo first order plot curve for Cd (11) ion removal using palm kernel shell at neutral pH.

The rate of Cd (II) ion adsorption showed none conformed to pseudo second order (Ho) as shown in Fig 6 and 7 for the sorbents.

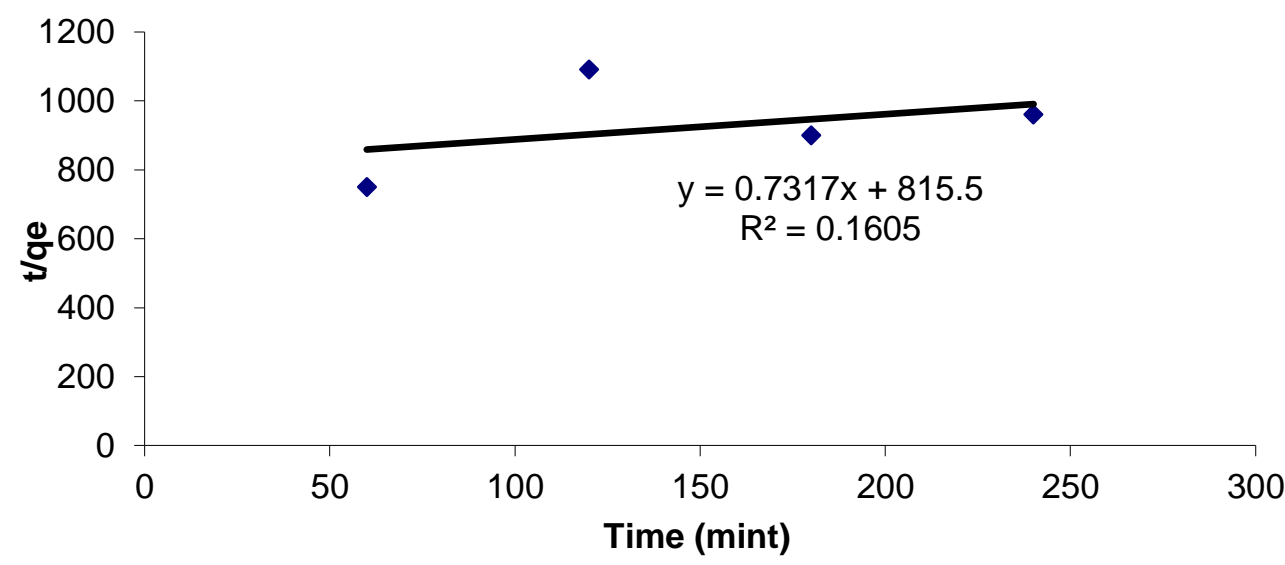

Fig 6: Pseudo second order plot for Cd (II) ion removal using coconut powder at neutral $\mathrm{pH}$ value

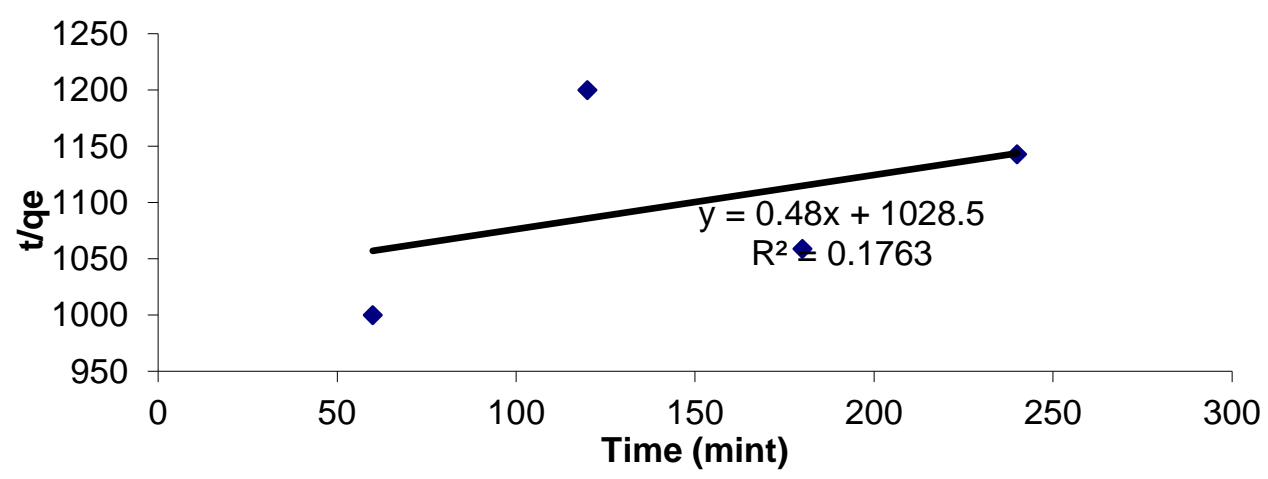

Fig 7: Pseudo second order plot for Cd (II) ion removal using palm kernel shell powder at neutral $\mathrm{pH}$ value

\section{Effect of $\mathrm{pH}$ on metal ion removal}

The $\mathrm{pH}$ of the metal ion solution is an important parameter for adsorption of metal ions because it affects the solubility of the metal ions, concentration of the counter ions on the functional groups of the adsorbent and the degree of ionization of the adsorbate. In the examination of the effect of $\mathrm{pH}$ on $\mathrm{Cd}$ (II) ion removal capacity for the two adsorbents, the $\mathrm{pH}$ was varied from 2.0 to 7.0 for $\mathrm{Cd}$ (II) but not at alkaline $\mathrm{pH}$ to prevent precipitation of metal hydroxides. As shown in Fig 8 the uptake of free ionic Cd (II) depends greatly on $\mathrm{pH}$ value, where optimal metal removal capacity occurs at $\mathrm{pH} 5.0$ and 6.0 for coconut shell and palm kernel shell adsorbents respectively. The $\mathrm{pH}$ of $\mathrm{Cr}(1 \mathrm{~V})$ on coconut shell is 4.5 which is closer that of $\mathrm{Cd}$ (II) ion (Babel and Kurniawan 2004). Removal capacity for Cd (II) increased from $0.21 \mathrm{mg} \mathrm{kg}^{-1}$ to $0.34 \mathrm{mg} \mathrm{kg}^{-1}$.over pH 
range from 2.0 to 4.0 for coconut shell adsorbent while palm kernel shell removal capacity increases from 0.16 $\mathrm{mg} \mathrm{kg}^{-1}$ at $\mathrm{pH} 2.0$ to $0.28 \mathrm{mg} \mathrm{kg}^{-1}$ at $\mathrm{pH}$ 6.0. The removal capacity decreases under acidic $\mathrm{pH}$ for the two adsorbents. This behavior is expected, as the acidity of the medium can affect the cadmium ion uptake on a biosorbent because hydrogen ions could compete with cadmium ions for active sites on the biosorbent surface (Nadeema,.et al 2009). The two adsorbents showed similar trends of adsorption but coconut shell powder showed much higher removal efficiency to palm kernel shell and slight different optimum pH value.

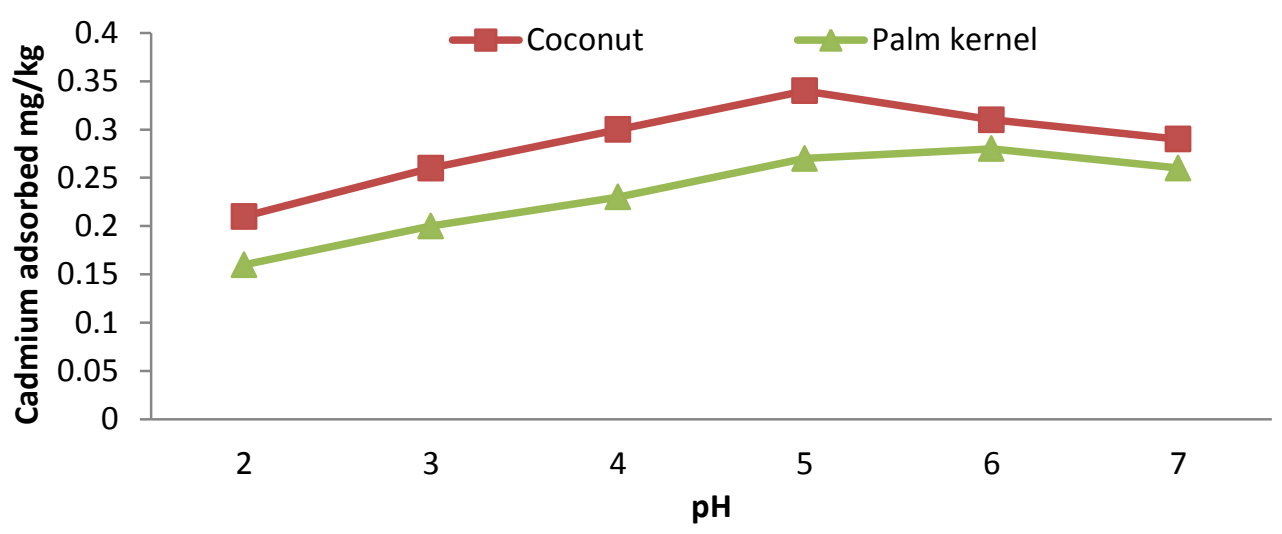

Figure 8: Effects of $\mathrm{pH}$ on the removal capacity of $\mathrm{Cd}$ (II) ion per unit mass each of coconut and Palm- kernel shells adsorbents

\section{Effect of ionic strength}

The Influence of ionic strength ( I) on heavy metal ions sorption by different sorbents (coconut and palm kernel shell adsorbents) was investigated to determine solution chemistry effects. Different ionic strength values $(0.2,0.4,0.6$ and $0.8 \mathrm{~g})$ were used by adding definite weights of solid $\mathrm{NaCl}$ to a definite concentration of the $\mathrm{Cd}(11)$ ion solutions $(1000 \mathrm{mg} / \mathrm{l})$. From the results obtained Fig 9 it could be seen that the increasing of the ionic strength results in a decrease in the amount of the $\mathrm{Cd}(11)$ ion adsorbed as a result of the competition between the $\mathrm{Cd}$ (11) ion and the salt ions ( Okieiman,.et al 1991). The reduction in uptake is probably due to the excess of $\mathrm{Na}+$ ions which inhibit the approach of adsorbed cadmium ions to the active sites of the sorbent each. Generally, there are two possible ways by which increasing ionic strength can influence metal ion sorption on different adsorbents. The decrease the solution-phase activity of metal ion or the increases in concentration of competing ion $(\mathrm{Na}+)$. So the increasing in ionic strength, there was a little decrease in $\mathrm{Cd}(11)$ ion removal which can be attributed to the presence of sorption sites of different affinities of coconut and palm kernel shells adsorbents

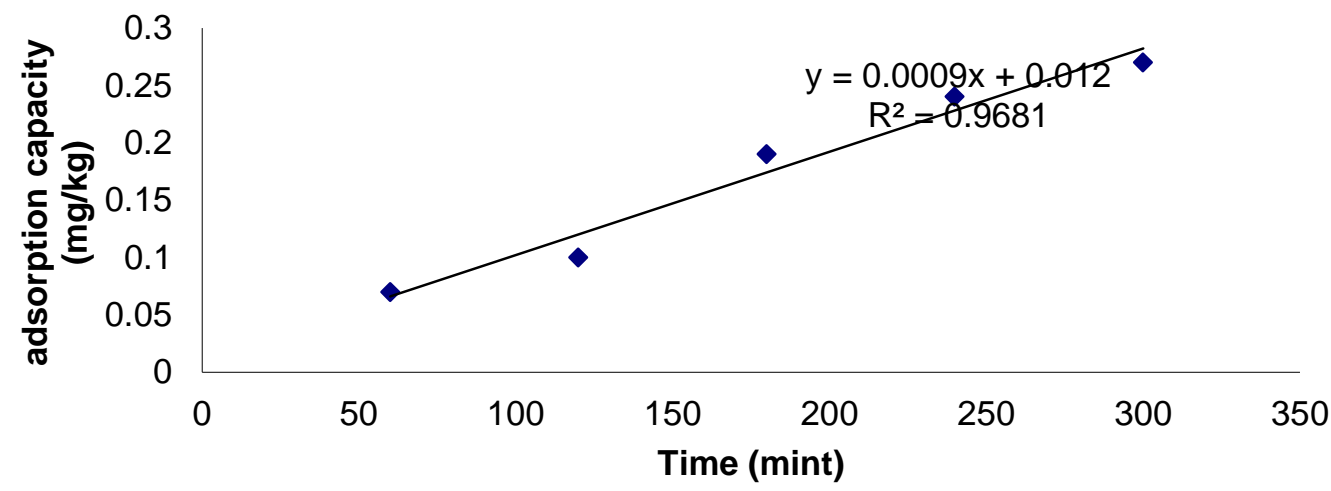

Fig 9: Effect of ionic strength on the removal capacity of Cd (II) ion using coconut shell adsorbent 


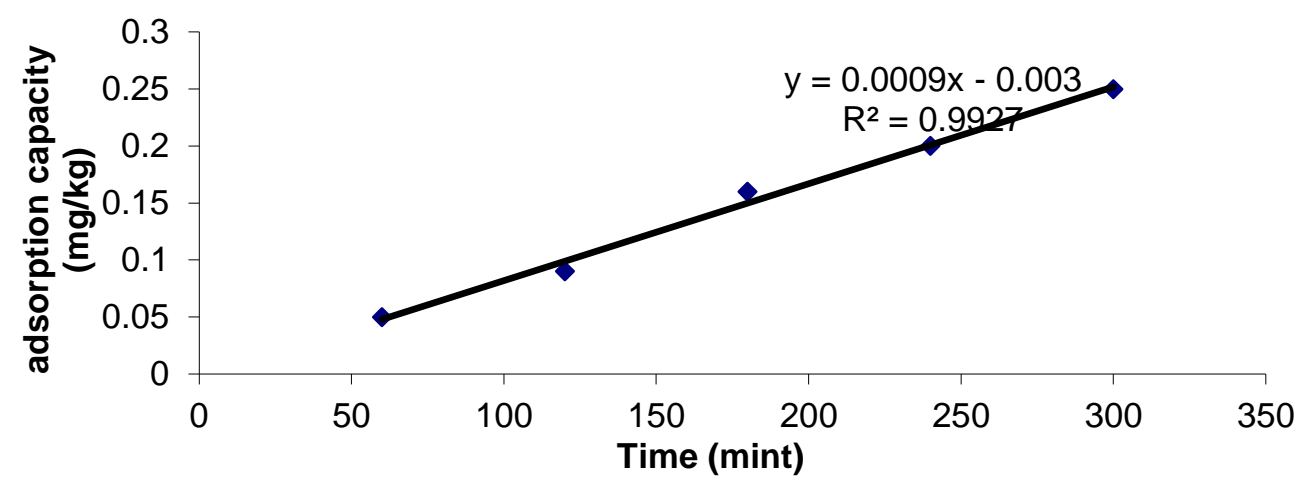

Fig 10: Effect of ionic strength on the removal capacity of Cd (II) ion using palm kernel shell adsorbent

\section{Adsorption isotherms}

To describe the adsorption isotherms Cd(II) ion onto coconut and palm kernel shell adsorbents, the two empirical models of Langmuir and Freundlich isotherms were tested. The adsorption studies were conducted per unit mass of adsorbent dosage $(1 \mathrm{~g})$ by varying initial concentrations of cadmium ions $(5,10,15$, and $20 \mathrm{mg} \mathrm{kg}^{-1}$ ). These isotherms relate metal uptake per unit weight of adsorbent $\mathrm{Q} e$ to the equilibrium metal ion concentration in the bulk phase $\mathrm{Ce}$.

\section{The Langmuir Model}

The Langmuir isotherm model is used to describe the relationship between the amounts of adsorbed material and its equilibrium concentration in solutions. The Langmuir isotherm is valid for monolayer adsorption on a surface containing finite number of identical sites. The model assumes a uniform adsorption on the surface and transmigration in the plane of the surface. The Langmuir isotherm is expressed as follows (Langmuir,. 1916.):

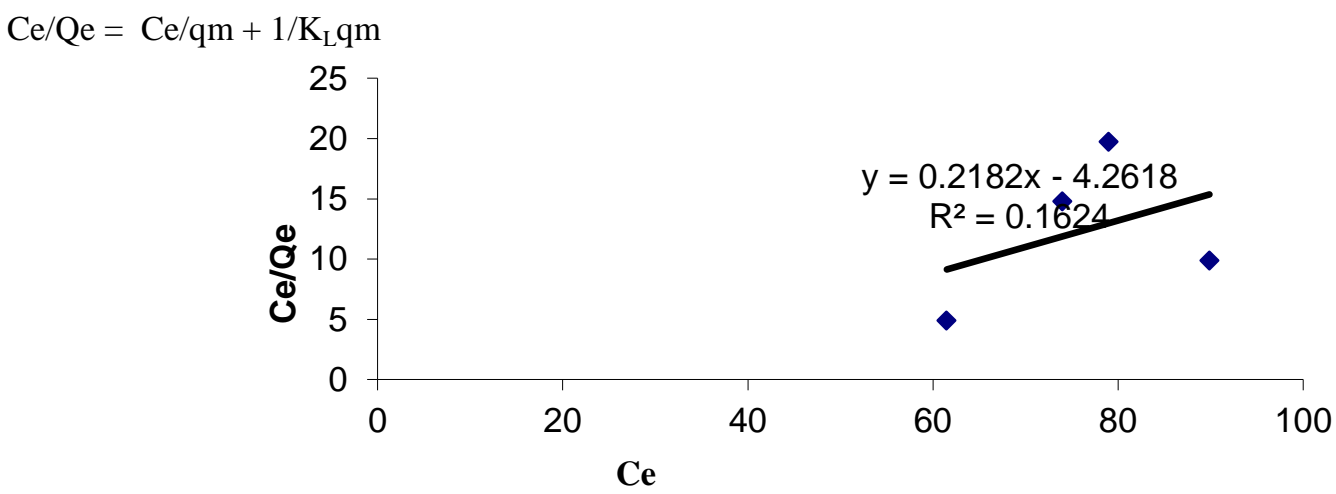

Fig 11: Langmuir isotherm plot for the adsorption of Cd (II) ion on coconut shell adsorbent at optimum pH.

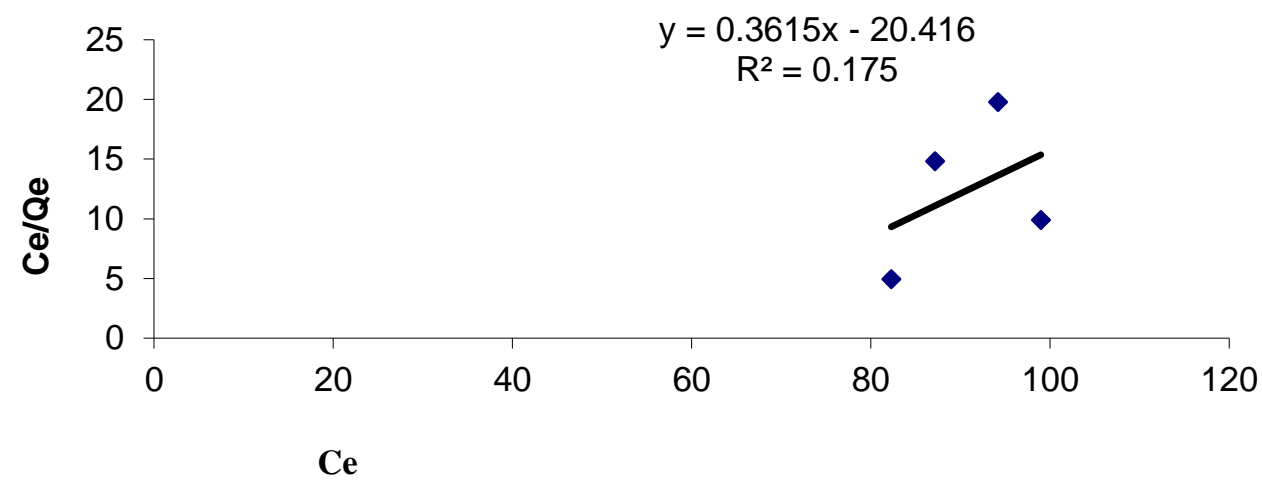

Fig 12: Langmuir isotherm plot for the adsorption of Cd (II) ion on palm kernel shell adsorbent at optimum pH . 


\section{The Freundlich Model}

The Freundlich isotherm assuming that the adsorption process takes place on heterogeneous surfaces and adsorption capacity is related to the concentration of the adsorbent. The Freundlich model is based on the following expression (Freundlich,.1906):

$\log \mathrm{Qe}=\log \mathrm{K}_{\mathrm{F}}+1 / \mathrm{n} \log \mathrm{Ce}$

$\mathrm{Qe}=$ the quantity of ions absorbed per unit weight of absorbent.

$\mathrm{Ce}=$ the equilibrium concentration of the adsorbate after adsorption has taken place.

"K $\mathrm{f}_{\mathrm{f}}$ = Freunlich constant; and " $1 / \mathrm{n}$ " = adsorption intensity.

Where $K_{F}\left(\mathrm{mg} \mathrm{g}^{-1}\right)$ is the Freundlich adsorption capacity and $1 / n$ is a constant indicating the reaction intensity. The two Freundlich parameters $K_{F}$ and $1 / n$ can be determined graphically from the intercept and slope of linear plot of $\log$ Qe against $\log$ Ce respectively (Fig $13 \& 14)$.

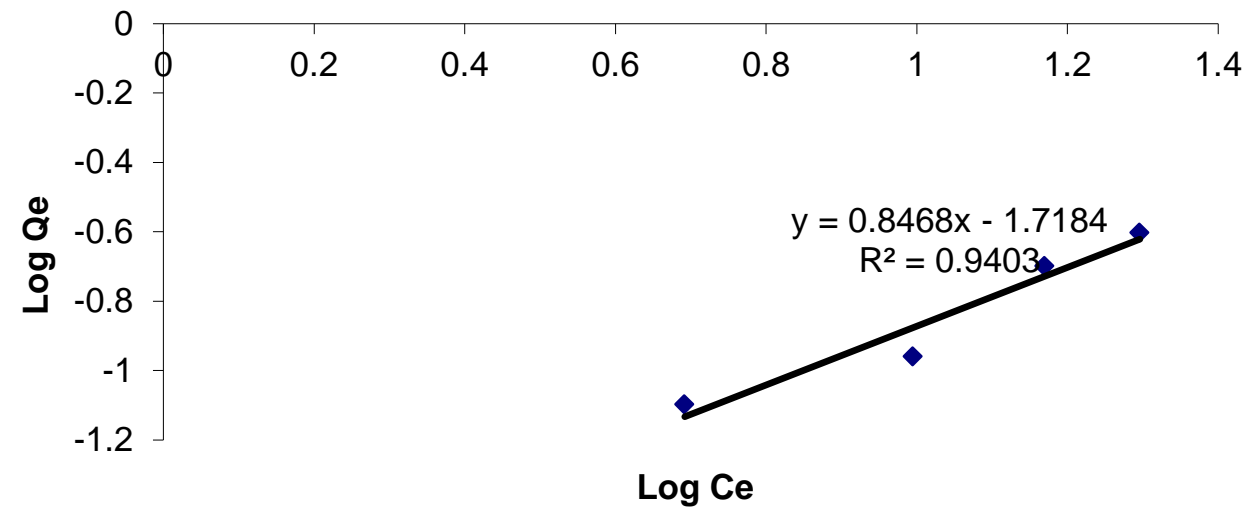

Figure 13: Freundlich isotherm plot for the adsorption of Cd (II) ion coconut shell adsorbents at optimum pH values

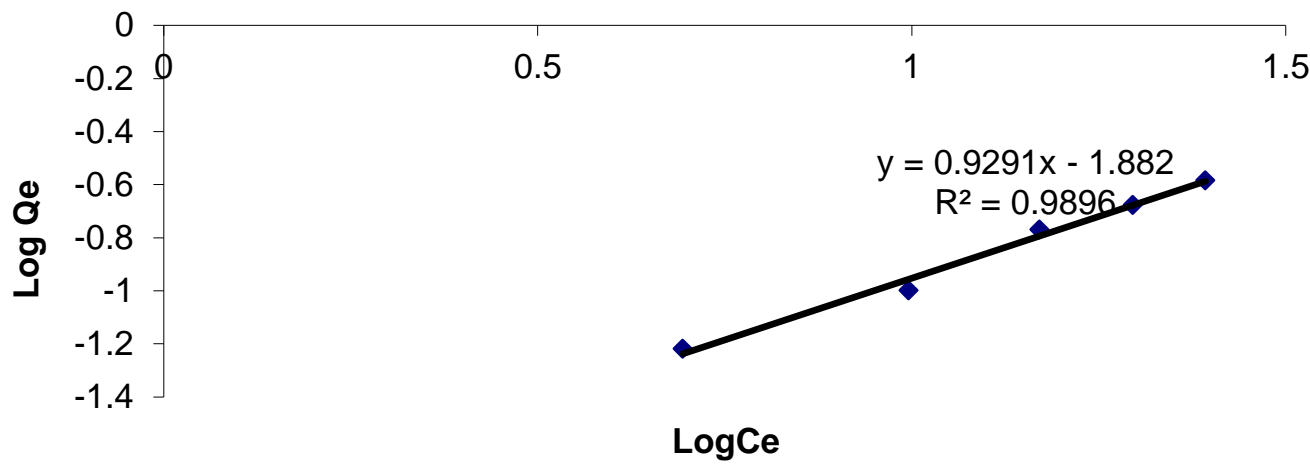

Fig 14: Freundlich isotherm plot for the adsorption of Cd (II) ion on palm kernel shell adsorbents at optimum pH values

Moreover the Freundlich coefficient $(1 / \mathrm{n})$ was smaller than one indicating that the adsorption of on the two adsorbents under studied condition was favorable. The correlation coefficients $\left(\mathrm{R}^{2}\right)$ are 0.94 and $0.99 \mathrm{for} \mathrm{Cd}$ (II) ion on coconut and palm kernel shells powder respectively. These results reveal that the Freundlich sorption isotherm is suitable for equilibrium studies for $\mathrm{Cd}$ (II) ion suggesting the formation of heterolayer coverage of the adsorbate on the surface of the adsorbents which agrees with the work of Pehlivan and Altun (2008) of chromium(VI) ion removal from aqueous solutions using walnut, hazelnut and almond shell adsorbent

The maximum adsorption capacities" $K_{F}$ " of the adsorbents calculated from Freundlich isotherm equation which defines the maximum capacity of the adsorbents for cadmium ions was found to be comparable with other adsorbents reported in the literature for $\mathrm{Cd}(\mathrm{II})$ ion on another adsorbent .

\section{Conclusion}

The experimental results indicated that coconut and palm kernel shell adsorbents can be successfully used for the adsorption of the Cd (II) ion from aqueous solutions. Experimental parameters such as initial metal concentrations, solution $\mathrm{pH}$, ionic strength and contact time must be optimally selected to obtain the highest 
possible removal of Cd (II) ion. The optimum equilibrium time were attained after 5 hrs of agitation and the kinetic mechanism is well described with the first order reaction kinetics. The results indicated that coconut shell adsorbent has higher adsorption capacity than palm kernel shells adsorbent and optimum $\mathrm{pH}$ of 5.0 and 6.0 , respectively for the adsorbents. Freundlich adsorption model fitted well with cadmium adsorption. Coconut and palm kernel shells which are agricultural waste material can be a good candidate for adsorption not only for this heavy metal selected, but also others in industrial and municipal wastewater stream or for industrial water treatment.

\section{Reference}

[1]. Babel,S and T.A. Kurniawan,(2004). Cr(VI) removal from synthetic wastewater using coconut shell charcoal and commercial activated carbon modified with oxidizing agent and/or

[2]. chitosan. Chemosphere, vol. 54, no.7, p. 951- 967.

[3]. Freundlich, H.M.F. 1906. Over the adsorption in solution. Journal of Physical Chemistry, 57:385-470.

[4]. Horsfall, M. and Abia, J.A. 2003. Sorption of cadmium (11) and zinc (1l) ions from aqeous solution by cassava waste biomass (manihot Sculenta) Crainz Research 37: 4913- 4923.

[5]. Horsfall, M.,Spiff A.L and Abia, A.A. 2004. Studies on the influence of Mercaptoacetic

[6]. ACID (MAA) Modification of Cassava (Manihot Sculenta Granz) waste biomass on Adsorption of Copper and Cadmium from solution. Bull Korean chemical society 25 (7): 969.

[7]. Horsfall, M. and Spiff, A.I. 2005. Equilibrium Sorption Study of $\mathrm{Al}^{3+} \mathrm{Co}^{2+} \mathrm{and}^{\mathrm{Ag}^{+}}$in

[8]. Aqueous Solutions by Fluted Pumpkin (Telfairia Occidentalis HOOK f) Waste Biomass. Acta Chimica Slovinica, 52: 174-181.

[9]. Ho, Y-S. and Ofomaja, A.E. 2006. Kinetic studies of copper ion adsorption on palm kernel

[10]. fibre, Journal of Hazardous Materials B, 137: 1796-1802. Horsfall, M. and Spiff, A.I. 2005. Equilibrium Sorption Study of Al ${ }^{3+}$, $\mathrm{Co}^{2+}$ and $\mathrm{Ag}^{+}$in

[11]. Aqueous Solutions by Fluted Pumpkin (Telfairia Occidentalis HOOK ) Waste Biomass. Acta Chimica Slovinica,52: 174-181..

[12]. Ho, Y.S. and Wang, C.C. 2004. Pseudo-isotherms for the sorption of cadmium ion onto tree fern. Process Biochemistry, 39: 761765.

[13]. Ho, Y-S. and Ofomaja, A.E. 2006. Kinetic studies of copper ion adsorption on palm kernel fibre, Journal of Hazardous Materials B, 137: 1796-1802.

[14]. Krishnan, K.A. and Anirudhan, T.S. 2003. Removal of cadmium(II) from aqueous solutions by Steam activated sulphurised carbon prepared from sugar-cane bagasse pith:kinetics and equilibrium studies. Water SA 29: 147-156.

[15]. Lagergren, S. 1898. About the theory of so-called adsorption of soluble Substances Kungliga Svenska.Ventenskapsakademience.Handlingar 24,1-39.

[16]. Langmuir, I. 1916. The constitution and fundamental properties of solids and liquids. Journal of American Chemical Society, 38: 2221-2295.

[17]. Loubna N,Ilhem Ghodbane, Qualid Hamdacious, Mahdichiha 2007. Batch sorption dynamic and equilibrium for the removal of cadmium ions from aqeous phase wheat bran. Journal of Hazardous Material. 149, 115-1

[18]. Low, K.S., Lee, C.K. and Liew, S.C. 2000. Sorption of cadmium and lead from aqueous solutions by spent grain. Process Biochemistry, 36: 59-64.

[19]. Naiya, T. K., Bhattacharya, A. K. and Das, S. K. 2009. Adsorptive removal of Cd(II) ions from aqueous solutions by rice husk ash. Environmental Progress in Chemical Engineering, 28: 535-546.

[20]. Okieiman, F.E., Okundla, E.V. and Ogbeifun, D.E. 1991. Sorption of cadmium and lead ions on modified groundnut (Arachis hypogea) husks. Journal of Chemical Technology and Biotechnology, 51: 97-103.

[21]. Pehlivan, E. and Altun, T. 2008. Biosorption of chromium(VI) ion from aqueous solutions using walnut, hazelnut and almond shell.Journal of Hazardous Materials, 155: 378-384.

[22]. Runping, H., Pan, H., Zhaohui, C., Zhenhui, Z. and Mingsheng, T. 2008. Kinetics and isotherms of Neutral Red adsorption on peanut husk. Journal of Environmental Science, 20: 1035-1041.

[23]. Saeed, A., Akhter, M.W. and Iqbal, M. 2005. Removal and recovery of heavy metals from aqueous solution using papaya wood as a new biosorbent. Separation and Purification Technology, 45: 25-31. 